\title{
Demografia genética dos índios Ticuna da Amazônia
}

\author{
Francisco M. Salzano $\left({ }^{*}\right)$ \\ Sidia M. Callegari Jacques $(\nRightarrow)$ \\ James V. Neel $\left({ }^{ \pm *} \leqslant\right)$
}

\begin{abstract}
REsumo
Os indios Ticuna do Brasil são atualmente uma tribo bastante aculturada e integrada, que habita, na sua maioria, aldeias localizadas ao longo do rio Solimões. São aqui apresentados dados demográficos coletados em oito destas aldeias, sendo que para cinco delas foram obtidas informaçōes minuciosas quanto à migração, fertilidıde e mortalidade. Os Ticuna caracterizamse por uma mobilidade relativamente grande, fertililidade alta (número médio de filhos nascidos vivos por mulher com $\geqslant 40$ anos : 7 ), baixa frequeência de casais estéreis $(2,5 \%)$ e uma mortalidade relativamente peque. na para grupos que vivem neste estágio cultural $(25 \%$ de mortes antes da idade de reprodução). A mortalidade baixa e uma variância também pequena no número de nascidos vivos em irmandades completas levaram a um indice de oportunidade para seleçäo igual a 0,54 o menor obtido até agora em populaçōes de indios sul-americanos.
\end{abstract}

\section{INTRODUÇÃo}

Os Ticuna (ou Tukuna) são provavelmente o maior grupo de descendentes de uma única tribo que ainda vive no Brasil. O número de pessoas que pertencem a esta tribo é da ordem de 11.000 , distribuídos em um território de $181.500 \mathrm{~km}^{2}$. Os limites de sua distribuição podem ser estabelecidos entre $2^{\circ}$ e $5^{\circ} \mathrm{S}$ e entre $66^{\circ}$ e $71^{\circ} 0$. Há indicações de que, no início do século 17 , eles se restringiam à região que circunda o rio Putumayo, na fronteira entre a Colômbia e o Peru. Com a extinção de seus inimigos tradicionais, os Omagua, que resultou da expansão da sociedade néobrasileira, os Ticuna foram ocupando gradualmente o território onde vivem atualmente.

A primeira menção histórica aos Ticuna parece ter sido feita por Cristóbal d'Acuña em 1641. Os contatos com espanhóis e por- tugueses iniciaram-se no século 17 e foram cheios de episódios de violência. Sua expansão geográfica e conseqüentes encontros com pioneiros não-índios durante os séculos 18, 19 e início do 20 levaram, de acordo com Oliveira (1964), a duas situações polares: a) os índios dos igarapés (tributários dos grandes rios), controlados em suas relações com o mundo exterior pelos negociantes de borra. cha; b) os índios dos rios, isto é, os que habitavam o posto indígena de Umariaçu e algumas outras comunidades néo-brasileiras, como Santa Rita do Weil, ao longo dos cursos d'água maiores. O sistema de exploração ao qual os índios dos igarapés estavam submetidos tinha como base o seu recrutamento como força de trabalho para a extração da borracha. O produto de seu trabalho nunca era suficiente para liberá-los da forte influência do patrão. Entretanto, quando a situação se tornava insustentável, eles tentavam fugir através da fronteira com a Colômbia, ou então surgia um movimento messiânico. Pelo menos seis destes movimentos foram descritos por M. V. Queiroz (citado por Oliveira, 1964) como tendo ocorrido no início deste século e resultado em migração para a região do rio Solimões.

Nimuendaju (1948) apresentou uma descrição sintética da cultura Ticuna pré-contato. Estes índios falam uma língua independente (ver também Loukotka, 1968) e a pesca teve sempre grande importância na sua subsistência. Quanto à sua organização social, estão divididos em duas metades exógamas patrilineares, sem denominação específica (Oliveira, 1964). Em épocas anteriores, a exogamia entre estes grupos era muito rígida; Nimuen-

\footnotetext{
( ") - Departamento de Genética, Instituto de Biociências, Univ. Federal do Rio Grande do Sul, Porto Alegre. $\left({ }^{*}\right)$ - Departamento de Estatística, Instituto de Matemática, Univ. Federal do Rio Grande do Sul, Porto Alegre. $\left({ }^{* *}\right)$ - Department of Human Genetics, University of Michigan Medical School, Ann Arbor, Michigan, USA.
} 
daju (1948) afirma que, em 1941, as violações ainda eram punidas com a morte. O infanticídio não era comum e raros os casos de bigamia. A coesão política entre os grupos não era forte e não há registro de que houvesse um chefe para toda a nação.

É importante observar que apesar de três séculos de contatos de naturezas diversas com os não-índios, os Ticuna ainda mantêm a sua identidade étnica e casamentos com pessoas de fora são raros. As razões para este fato poderiam ser: a) a violência que esteve presente com freqüência nas relações entre os Ticuna e o mundo exterior; b) a baixa densidade populacional de pessoas não-índias na área ocupada por esta tribo; c) o sistema de exploração da borracha, que forçava estes índios ao isolamento nos igarapés; d) a tradição cultural da tribo que, como foi mencionado antes, favorecia casamentos intratribais exogâmicos.

Oliveira (1964) realizou um recenseamento minucioso em quatro localidades habitadas por estes índios em 1959 e 1962. Mas o tamanho e a composição destas populações mudaram dramaticamente desde então, face ao movimento denominado "Santa Cruz". Esta nova religião foi criada pelo irmão José Francisco da Cruz, que nasceu em Minas Gerais em 1913 e afirma ter tido uma Visão Celestial em 1934. Começou ele seu trabaiho apostólico em 1962 e, após peregrinações no sul do Brasil e no Peru, penetrou na área Ticuna em 1972. Carregando sempre uma cruz e uma bíblia, ele erigiu, com a ajuda de discípulos e apesar da oposição dos padres católicos, 31 cruzes em vários pontos das margens do rio Solimões. Dezessete deste total foram colocadas em localidades habitadas por índios Ticuna (Umariaçu - 2 cruzes, Cleto, Bom Jardim, Sabonete, Capacete, Feijoal, Belém, Palmares, Bananal, Cajari, Vendaval, Santa Rita do Weil, Niterói - 2 cruzes, Nova ltália e Boca do Içá). Elas então se tornaram polos de atração, aos quais convergiram muitas famílias indígenas. Atualmente o Irmão José vive em um lugar às margens do rio Içá. A fácil conversão dos Ticuna a esta religião pode ser explicada parcialmente pelo fato de que os movimentos messiânicos já faziam parte integrante da herança cultural desta tribo.

Estudos demográficos nestes índios foram realizados por Oliveira (1977) e Oliveira Filho (1977). Estas e outras investigações anteriores fornecem bom material para ser comparado com os resultados que serão descritos a seguir. Nós obtivemos dados demográfi cos e genéticos em oito comunidades; a demografia será pormenorizada nesta comunicação, porém, face a problemas de espaço, os resultados referentes aos marcadores genéticos serão apresentados em outro artigo.

MATERIAL E MÉTODOS

Os dados foram coletados de 14 de julho a 17 de agosto de 1976 , em oito comunidades Ticuna distribuídas ao longo do rio Solimões e indicadas na Fig. 1 pelos números: 1: Umatiaçu; 2: Bom Jardim; 15: Marajá; 16: Feijoal: 20: Belém; 26: Vendaval; 31: Campo Alegre e 55: Nova Itália. Estes estudos foram desenvolvidos como parte de uma expedição multidisciplinar, cujo objetivo era pesquisas científicas biomédicas e físicas, que utilizou as instalações do navio Alpha Helix. As oito aldeias não foram estudadas com a mesma intensidade. A informação é mais completa com relação a 5 delas : Umariaçu, Belém, Vendaval, Campo Alegre e Nova Itália. Em Bom Jardim, Marajá e Feijoal foram obtidos dados apenas quanto a familias nucleares que haviam sido estudadas quanto aos marcadores genéticos e outras investigações biomédicas.

Os estudos mais pormenorizados incluíram entrevistas com um ou ambos os membros de cada casal, que geralmente compareciam ao exame acompanhados dos filhos. As perguntas relacionavam-se a : (1) nome, idade e grupo étnico dos cônjuges; (2) local de nascimento; (3) nomes e idades dos pais; (4) nomes e sexo dos irmãos que viviam na localicade; (5) número de filhos vivos e mortos; (6) abortos; (7) nomes, sexo e idade dos filhos vivos; (8) idade e sexo dos filhos mortos; (9) informação sobre os que tinham deixado a comunidade; (10) outros casamentos de um ou ambos os esposos; (11) outras pessoas vivendo com a família; (12) número de anós de coabitação, nos casamentos sem filhos. 


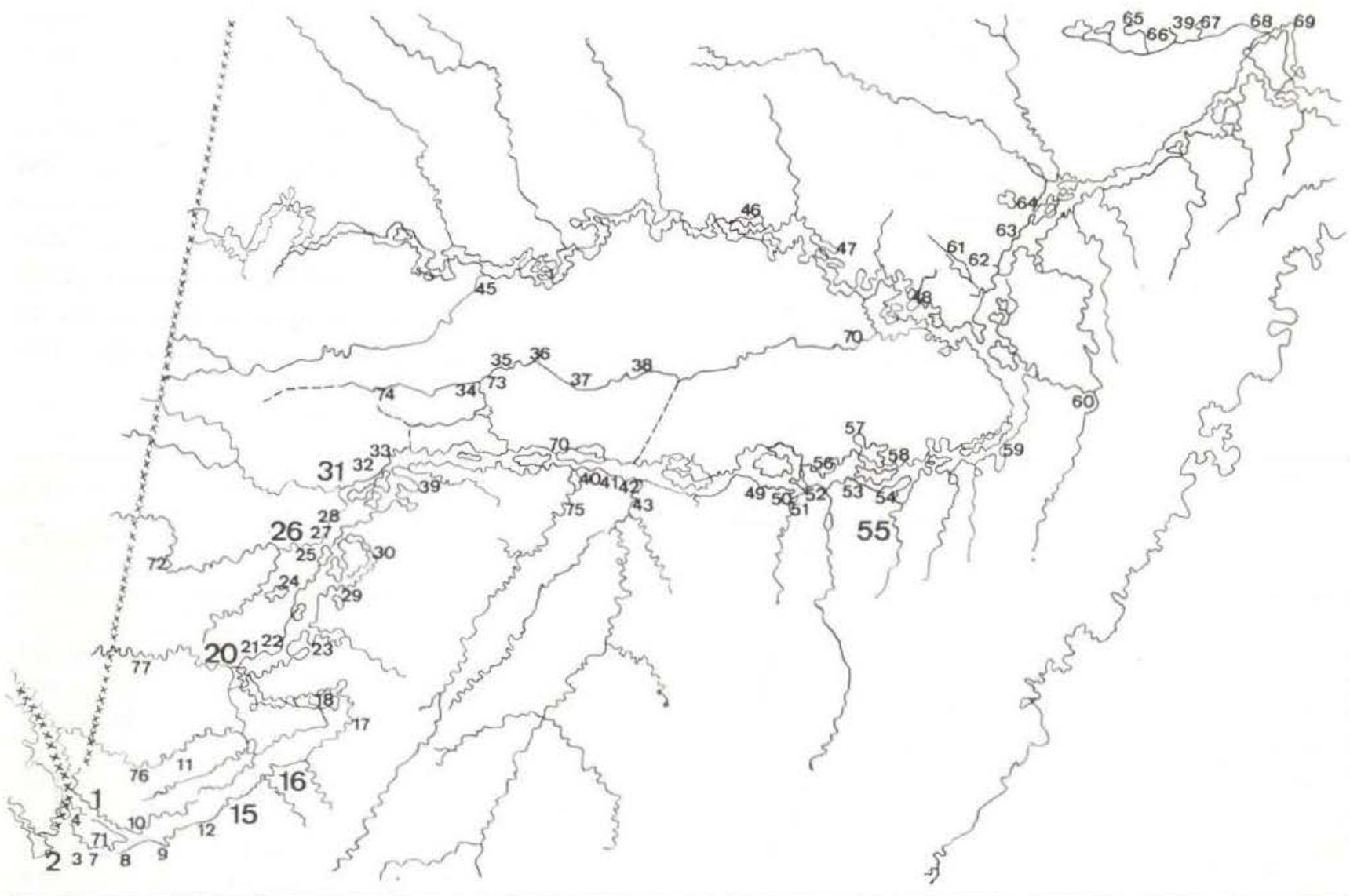

Fig. 1 - Mapa da região oeste do Estado do Amazonas, onde está localizada a maioria das comunidades Ticuna. Estende-se de $2^{\circ} 5^{\prime}$ a $4^{\circ} 5^{\prime} \mathrm{S}$ e de $67^{\circ} 3^{\prime}$ a $70^{\circ} 0$. O rio principal que cruza toda a região, desde o quadrante inferior esquerdo até o superior direito. é o Solimōes. O maior afluente mostrado na sua margem esquerda é o rio Içá, chamado Putumayo na Colômbia e no Peru. Os números maiores indicam as aldeias onde foram obtidos dados demográficos. Temos à disposição, para quem solicitar, uma lista com os nomes de todas as localidades indicadas no mapa (Reproduzido, com algumas modificaçōes, de Oliveira Filho, 1977).

Estas entrevistas eram sempre conduzidas com o auxilio de intérpretes, pois embora a maioria dos homens fosse bilingüe, tinham eles alguma dificuldade em expressar-se em português. O conhecimento desta língua era ainda menor entre as mulheres. Os intérpretes entendiam bem o português e geralmente tinham posição social alta na comunidade. Eles também auxiliaram, em muitos casos, na verificação da fidedignidade das informaçōes dadas. As idades de todas as pessoas foram estimadas por inspeção visual, fazendo-se comparações entre os valores obticos em pais e filhos, a fim de chegar-se a uma conclusão final.

\section{RESUlTADOS}

As distribuições de idade e sexo de 3.300 indivíduos, registrados no recenseamento por- menorizado, são apresentadas na Tabela 1. $\mathrm{Na}$ Tabela 2, estão informações adicionais a respeito de 1.684 pessoas, que tomaram parte ou foram mencionadas em outros estudos. As diferenças entre localidades não são estatisticamente significativas. A idade média de 23 anos, para homens, e de 24 , aproximadamente, para as mulheres, é maior do que as observadas em tribos menos aculturadas de indios sul-americanos; mas a percentagem de pessoas na categoria $0-14$ anos $(41 \%)$ é aproximadamente a mesma encontrada nestes grupos (ver revisão em Salzano, 1972). O número de homens e mulheres é aproximadamente o mesmo, com proporção sexual elevada entre os mais jovens, conforme o esperado. Os indivíduos incluídos na Tabela 2 são em geral mais velhos, mesmo se levarmos em conta a falta de crianças no intervalo 0-5 
anos. Isto, certamente, é um efeito do sistema de amostragem; os voluntários para a coleta de sangue são geralmente mais velhos do que as pessoas que evitam estas coletas.

Há relativamente poucos indivíduos com ancestrais não-índios (menos de $1 \%$ ) ou ancestrais mistos $(8 \%)$ nas aldeias mais estudadas (Tabela 3). Quanto às três localidades restantes, somente em Feijoal apareceram pessoas deste tipo, com uma freqüência total de $9 \%$. A grande quantidade de mestiços observada em Umariaçu era esperada, face à proximidade deste local com Letícia, Tabatinga e Benjamim Constant, que são comunidades não-índias relativamente populosas. Por outro lado, se excluímos da amostra os indivíduos que se auto-denominaram como "misturados" ou néo-brasileiros, resta muito pouca evidência de mistura. Para toda a tribo, os dados relativos ao sistema genético $\mathrm{Gm}$ indi-

TABELA 1 - Distribuição, por sexo e idade, dos habitantes de cinco localidades Tícuna.

\begin{tabular}{|c|c|c|c|c|c|c|}
\hline \multirow{2}{*}{$\begin{array}{l}\text { Localidade } \\
\text { e sexo }\end{array}$} & \multicolumn{3}{|c|}{ Faixa etária } & \multirow{2}{*}{$\begin{array}{l}\text { Idade } \\
\text { desconhecida }\end{array}$} & \multirow[t]{2}{*}{ Total } & \multirow{2}{*}{$\begin{array}{l}\text { Idade média } \\
\text { estimada } \\
(M \pm D P)\end{array}$} \\
\hline & $0-14$ & $15-30$ & $>30$ & & & \\
\hline \multicolumn{7}{|l|}{ Umariaçu } \\
\hline Homens & 170 & 108 & 129 & 220 & 627 & $23,1 \pm 18,6$ \\
\hline Mulheres & 165 & 120 & 124 & 211 & 620 & $23,6 \pm 18.5$ \\
\hline Total & 335 & 228 & 253 & 431 & 1247 & $23,3 \pm 18,5$ \\
\hline Fercentagem & 41,1 & 27,9 & 31,0 & $\ldots$ & $\ldots$ & $\ldots$ \\
\hline Proporção sexual & 103 & 90 & 104 & 104 & 101 & $\cdots$ \\
\hline \multicolumn{7}{|l|}{ Belém } \\
\hline Homens & 72 & 47 & 60 & 121 & 300 & $24.4 \pm 18.3$ \\
\hline Mulheres & 79 & 51 & 58 & 112 & 300 & $22,7 \pm 17,8$ \\
\hline Total & 151 & 98 & 118 & 233 & 600 & $23.5 \pm 18,0$ \\
\hline Percentagem & 41,1 & 26,7 & 32,2 & $\ldots$ & $\cdots$ & $\ldots$ \\
\hline Proporção sexual & 91 & 92 & 103 & 108 & 100 & $\ldots$ \\
\hline \multicolumn{7}{|l|}{ Vendaval } \\
\hline Homens & 81 & 47 & 54 & 92 & 274 & $22,6 \pm 18,1$ \\
\hline Mulheres & 58 & 38 & 55 & 72 & 223 & $25,1 \pm 17,8$ \\
\hline Total & 139 & 85 & 109 & 164 & 497 & $23,7 \pm 18,0$ \\
\hline Percentagem & 41,8 & 25,5 & 32.7 & $\ldots$ & $\ldots$ & $\ldots$ \\
\hline Proporção sexual & 140 & 124 & 98 & 128 & 123 & $\cdots$ \\
\hline \multicolumn{7}{|l|}{ Campo Alegre } \\
\hline Homens & 106 & 50 & 76 & 169 & 401 & $23,0 \pm 18,2$ \\
\hline Mulheres & 79 & 54 & 82 & 119 & 334 & $24,7 \pm 18,3$ \\
\hline Total & 185 & 104 & 158 & 288 & 735 & $23,8 \pm 18.2$ \\
\hline Percentagem & 41.4 & 23,3 & 35,3 & $\ldots$ & $\cdots$ & $\cdots$ \\
\hline Proporção sexual & 134 & 93 & 93 & 142 & 120 & $\cdots$ \\
\hline \multicolumn{7}{|l|}{ Nova Itália } \\
\hline Homens & 23 & 19 & 25 & 45 & 112 & $262 \pm 18,8$ \\
\hline Mulheres & 35 & 17 & 26 & 31 & 109 & $23,4 \pm 17,6$ \\
\hline Total & 58 & 36 & 51 & 76 & 221 & $24,7 \pm 18,1$ \\
\hline Percentagem & 40,0 & 24,8 & 35,2 & $\ldots$ & $\cdots$ & $\cdots$ \\
\hline Proporção sexual & 66 & 112 & 96 & 145 & 103 & $\cdots$ \\
\hline \multicolumn{7}{|c|}{ Todas as localidades } \\
\hline Homens & 452 & 271 & 344 & 647 & 1714 & $23,0 \pm 18,4$ \\
\hline Mulheres & 416 & 280 & 345 & 545 & 1586 & $23.8 \pm 18,2$ \\
\hline Total & 868 & 551 & 689 & 1192 & 3300 & $23,6 \pm 18,3$ \\
\hline Percentagem & 41,2 & 26,1 & 32,7 & $\ldots$ & $\cdots$ & $\ldots$ \\
\hline Proporção sexual & 109 & 97 & 100 & 119 & 108 & $\cdots$ \\
\hline
\end{tabular}

M: média; DP: desvia padrão. 
TABELA 2 - Informações complementares obtidas em outros indivíduos da tribo Ticuna

\begin{tabular}{|c|c|c|c|c|}
\hline \multirow{2}{*}{$\begin{array}{l}\text { Localidade } \\
\text { e sexo }\end{array}$} & \multicolumn{3}{|c|}{ Faixa etária } & \multirow[t]{2}{*}{ Total } \\
\hline & $0-14$ & $15-30$ & $>30$ & \\
\hline \multicolumn{5}{|l|}{ Bom Jardim } \\
\hline Homens & 22 & 17 & 24 & 63 \\
\hline Mulheres & 22 & 21 & 20 & 63 \\
\hline Total & 44 & 38 & 44 & 126 \\
\hline Percentagem & 34,9 & 30,2 & 34,9 & $\ldots$ \\
\hline Proporção sexual & 100 & 81 & 120 & 100 \\
\hline \multicolumn{5}{|l|}{ Marajá } \\
\hline Homens & 19 & 18 & 30 & 67 \\
\hline Mulheres & 18 & 24 & 33 & 75 \\
\hline Total & 37 & 42 & 63 & 142 \\
\hline Percentagem & 26,1 & 29.6 & 44,3 & $\ldots$ \\
\hline Proporção sexual & 106 & 75 & 91 & 89 \\
\hline \multicolumn{5}{|l|}{ Feijoal } \\
\hline Homens & 39 & 32 & 43 & 114 \\
\hline Mulheres & 34 & 37 & 42 & 113 \\
\hline Total & 73 & 69 & 85 & 227 \\
\hline Percentagem & 32,2 & 30,4 & 37.4 & $\ldots$ \\
\hline Proporção sexual & 115 & 86 & 102 & 101 \\
\hline \multicolumn{5}{|l|}{ Belém } \\
\hline Homens & 26 & 30 & 89 & 145 \\
\hline Mulheres & 28 & 36 & 79 & 143 \\
\hline Total & 54 & 66 & 168 & 288 \\
\hline Percentagem & 18,8 & 22,9 & 58,3 & . \\
\hline Proporção sexual & 93 & 83 & 113 & 101 \\
\hline \multicolumn{5}{|l|}{ Vendaval } \\
\hline Homens & 30 & 44 & 80 & 154 \\
\hline Mulheres & 26 & 45 & 71 & 142 \\
\hline Total & 56 & 89 & 151 & 296 \\
\hline Percentagem & 18,9 & 30,1 & 51,0 & $\cdots$ \\
\hline Proporção sexual & 115 & 98 & 113 & 109 \\
\hline \multicolumn{5}{|l|}{ Campo Alegre } \\
\hline Homens & 46 & 65 & 120 & 231 \\
\hline Muiheres & 43 & 72 & 109 & 224 \\
\hline Total & 89 & 137 & 229 & 455 \\
\hline Percentagem & 19,6 & 30.1 & 50,3 & .. \\
\hline Proporção sexual & 107 & 90 & 110 & 103 \\
\hline \multicolumn{5}{|l|}{ Nova Itália } \\
\hline Homens & 13 & 16 & 46 & 75 \\
\hline Mulheres & 12 & 23 & 40 & 75 \\
\hline Total & 25 & 39 & 86 & 150 \\
\hline Percentagem & 16,7 & 26,0 & 57,3 & $\cdots$ \\
\hline Proporção sexual & 108 & 70 & 115 & 100 \\
\hline \multicolumn{5}{|c|}{ Todas as localidades } \\
\hline Homens & 195 & 222 & 432 & 849 \\
\hline Mulheres & 183 & 258 & 394 & 835 \\
\hline Total & 378 & 480 & 826 & 1684 \\
\hline Percentagem & 22,4 & 28,5 & 49,1 & ... \\
\hline Proporção sexual & 107 & 86 & 110 & 102 \\
\hline
\end{tabular}

(1) - Freqüências ajustadas devido à falta de informaçâo à respeito de crianças com $0-5$ anos de idade. cam somente 0,009 de mistura com caucasóides e 0,003 de mistura com negros; as tipagen quanto ao $A B O$ confirmam estes resulta. dos (Gershowitz et al., não publicado).

Os Ticuna estão espalhados por um grande número de comunidades, conforme é mostrado na Fig. 1. A tendência para o agrupamento em populações maiores, como mencionado anteriormente, é um fenômeno recente, estimulado pelo movimento da Santa Cruz. A Tabela 4 informa sobre o grau de exogamia nas cinco localidades estudadas quanto a este aspecto. Há uma dicotomia clara entre Be. lém e Vendaval, por um lado, e Umariaçu, Campo Alegre e Nova Itália, por outro. As duas primeiras mostram uma percentagem relativamente alta de casamentos nos quais ambos os cônjuges são naturais do próprio lugar $(73 \%$ e $76 \%$ respectivamente), enquanto que, nas três restantes, esta percentagem é bem menor $(5 \%-16 \%)$. No entanto, deve esclarecer-se que, para todas, o número de localidades indicadas como local de nascimento dos cônjuges é grande (de 10, em Vendaval, a 45 em Umariaçu; número total : 67).

Dados adicionais sobre os padrões de migração estẫo apresentados nas Tabelas 5 e 6 . As distâncias entre os locais de nascimento dos adultos férteis e o lugar onde eles atualmente vivem varia de zero a $608 \mathrm{~km}$. A maioria das localidades, no entanto, está dentro de um raio de $150 \mathrm{~km}$ da comunidade onde estes indivíduos foram estudados. As exceções referem-se à Nova Itália, onde $58 \%$ dos adultos nasceram em locais situados a mais de $200 \mathrm{~km}$ de distância. Pode também verificarse que as distâncias médias são muito pequenas em Vendaval e Belém ( 7 e $12 \mathrm{~km}$, respec. tivamente), aumentando gradativamente nas outras comunidades até o valor máximo de $147 \mathrm{~km}$, encontrado em Nova Itália (Tabela 5). A matriz estocástica retroativa de migração, apresentada na Tabela 6 , reflete a grande quantidade de exogamia encontrada. Pessoas que nasceram em Belém contribuíram para o reservatório gênico das outras quatro localida. des. As que nasceram em Vendaval também aparecem como genitores em três das quatro aldeias restantes. Por outro lado, indivíduos nascidos em Nova Itália não estão representa. 
TABELA 3 - Mistura racial em cinco comunidades de índios Ticuna

\begin{tabular}{|c|c|c|c|c|c|c|c|}
\hline \multirow[t]{2}{*}{ Localidade } & \multicolumn{2}{|c|}{ Índios } & \multicolumn{2}{|c|}{ Mistos ${ }^{1}$} & \multicolumn{2}{|c|}{ Não-Indios² } & \multirow[t]{2}{*}{ Total } \\
\hline & $\mathrm{N}$ & $\%$ & $\mathrm{~N}$ & $\%$ & $\mathrm{~N}$ & $\%$ & \\
\hline Umariaçu & 1047 & 84 & 193 & 15 & 9 & 1 & 1249 \\
\hline Belém & 539 & 95 & 23 & 4 & 4 & 1 & 566 \\
\hline Vendaval & 464 & 96 & 19 & 4 & 0 & 0 & 483 \\
\hline Campo Alegre & 711 & 99 & 8 & 1 & 0 & 0 & 719 \\
\hline Nova Itália & 215 & 100 & 0 & 0 & 0 & 0 & 215 \\
\hline Todas as localidades & 2976 & 92 & 243 & 8 & 13 & $<1$ & 3232 \\
\hline
\end{tabular}

(1) - Confirmado ou suspeito; (2) - Néo-brasileiros ou néo-peruanos, $\mathrm{N}$ : Número de indivíduos.

TABELA 4 - Casamentos endogâmicos e exogâmicos em cinco comunidades de índios Tícuna

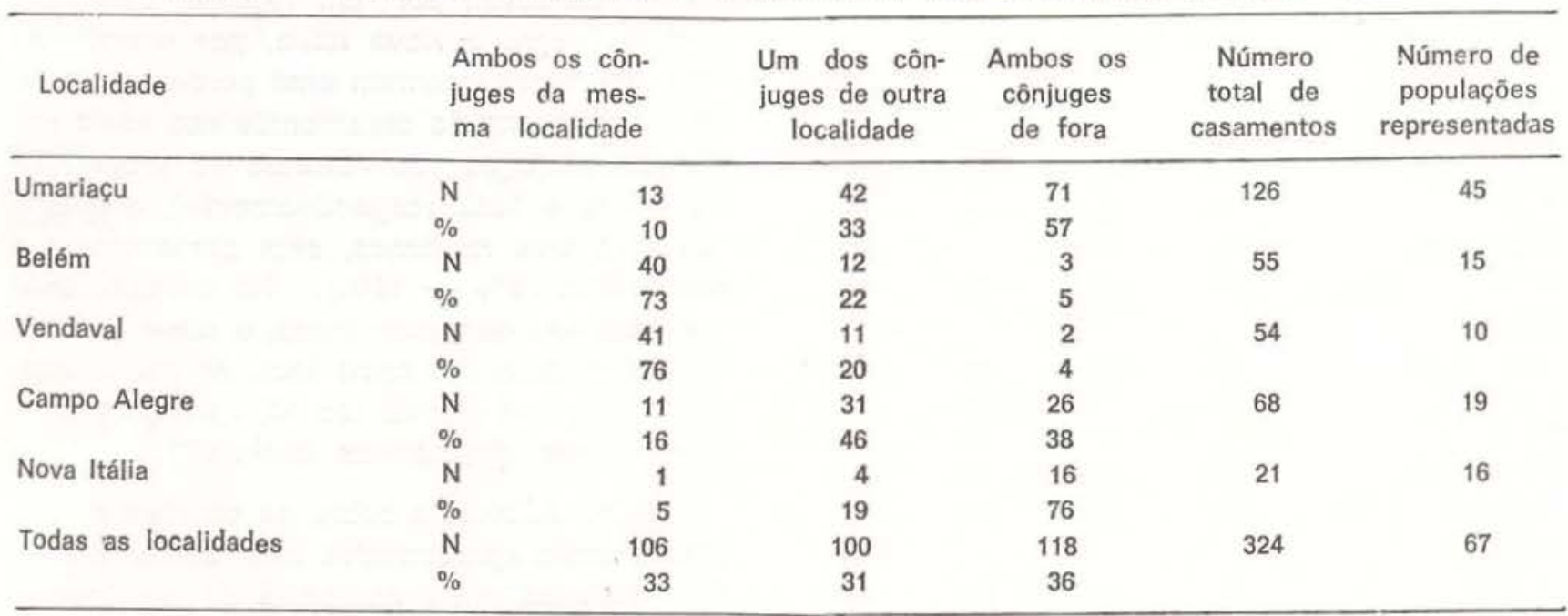

N: Número de casomentos.

TABELA 5 - Distância entre o local de nascimento e o de residência atual dos Ticuna adultos férteís

\begin{tabular}{|c|c|c|c|c|c|c|c|c|c|c|c|}
\hline \multirow{2}{*}{$\begin{array}{l}\text { Residência } \\
\text { atual }\end{array}$} & \multicolumn{10}{|c|}{ Distância do local de nascimentc (em km) } & \multirow{2}{*}{$\begin{array}{r}\text { Número } \\
\text { total }\end{array}$} \\
\hline & & zero & $1-50$ & $51-100$ & $101-150$ & $151-200$ & $\angle 01-250$ & $251-300$ & $>300$ & Média $\pm E P$ & \\
\hline \multirow[t]{3}{*}{ Umariaçu } & No. indiv. & 66 & 72 & 47 & 26 & 0 & 17 & 2 & 6 & 67 & 236 \\
\hline & $\%$ & 28 & 30 & 20 & 11 & 0 & 7 & 1 & 3 & \pm 5 & $\ldots$ \\
\hline & No. local. & 1 & 12 & 7 & 4 & 0 & 6 & 2 & 4 & $\ldots$ & 36 \\
\hline \multirow[t]{3}{*}{ Belém } & No. indiv. & 86 & 10 & 2 & 1 & 0 & 2 & 1 & 0 & 12 & 102 \\
\hline & $\%$ & 84 & 10 & 2 & 1 & 0 & 2 & 1 & 0 & \pm 4 & $\ldots$ \\
\hline & No. local. & 1 & 7 & 2 & 1 & 0 & 1 & 1 & 0 & $\ldots$ & 13 \\
\hline \multirow[t]{3}{*}{ Vendaval } & No. indiv. & 88 & 9 & 0 & 1 & 1 & 1 & 0 & 0 & 7 & 100 \\
\hline & $\%$ & 88 & 9 & 0 & 1 & 1 & 1 & 0 & 4 & \pm 3 & $\ldots$ \\
\hline & No. local. & 1 & 4 & 0 & 1 & 1 & 1 & 0 & 0 & $\ldots$ & 8 \\
\hline \multirow[t]{3}{*}{ Campo Alegre } & No. indiv. & 46 & 43 & 20 & 6 & 1 & 3 & 0 & 0 & 32 & 119 \\
\hline & $\%$ & 39 & 36 & 17 & 5 & 1 & 2 & 0 & 0 & \pm 5 & $\ldots$ \\
\hline & No. local. & 1 & 6 & 5 & 1 & 1 & 1 & 0 & 0 & $\ldots$ & 15 \\
\hline \multirow[t]{3}{*}{ Nova Itália } & No. indiv. & 6 & 5 & 4 & 2 & 0 & 22 & 1 & 1 & 147 & 41 \\
\hline & $\%$ & 15 & 12 & 10 & 5 & 0 & 54 & 2 & 2 & \pm 16 & $\ldots$ \\
\hline & No. local. & 1 & 3 & 3 & 1 & 0 & 5 & 1 & 1 & $\ldots$ & 15 \\
\hline
\end{tabular}

NOTA: O número de localidades incluidos nesta tabela é menor do que os apresentados nas Tabelos 4 e 6 porque 15 das 67 mencionadas năo puđeram ser localizadas, com exatidăo, no mapa. EP: Erro padrōo da média. 
TABELA 6 - Matriz estocástica retroativa de migração para cinco populaçōes de indios Ticuna

\begin{tabular}{|c|c|c|c|c|c|c|}
\hline \multirow[t]{2}{*}{$\begin{array}{l}\text { Local de nascimento } \\
\text { dos pais }\end{array}$} & \multicolumn{5}{|c|}{$\begin{array}{l}\text { Local de nascimento } \\
\text { dos filhos }\end{array}$} & \multirow[t]{2}{*}{ Total } \\
\hline & $\mathrm{U}$ & B & VD & $\mathrm{CA}$ & NI & \\
\hline U & 237 & 5 & 0 & 0 & 0 & 242 \\
\hline B & 150 & 338 & 18 & 30 & 22 & 558 \\
\hline VD & 30 & 7 & 318 & 64 & 0 & 419 \\
\hline CA & 49 & 0 & 23 & 220 & 0 & 292 \\
\hline $\mathrm{NI}$ & 0 & 0 & 0 & 0 & 2.5 & 25 \\
\hline 0 & 194 & 8 & 0 & 0 & 16 & 218 \\
\hline VZ & 38 & 0 & 0 & 0 & 0 & 38 \\
\hline LA & 0 & 4 & 0 & 41 & 0 & 45 \\
\hline IP & 13 & 0 & 0 & 36 & 1 & 50 \\
\hline IA & 27 & 10 & 0 & 21 & 0 & 58 \\
\hline IC & 23 & 0 & 0 & 4 & 3 & 30 \\
\hline SJ & 20 & 0 & 0 & 0 & 0 & 20 \\
\hline SD & 0 & 0 & 5 & 24 & 0 & 29 \\
\hline RJ & 7 & 0 & 0 & 21 & 7 & 35 \\
\hline$A P$ & 0 & 0 & 0 & 0 & 28 & 28 \\
\hline s & 16 & 11 & 0 & 0 & 0 & 27 \\
\hline IT & 0 & 0 & 0 & 0 & 15 & 15 \\
\hline Outras & 274 & 29 & 8 & 58 & 50 & 419 \\
\hline Total & 1078 & 412 & 372 & 519 & 167 & 2548 \\
\hline $\begin{array}{l}\text { N.o de populações } \\
\text { incluídas na } \\
\text { categoria "Outras" }\end{array}$ & (33) & (8) & (6) & $(7)$ & (8; & (48) \\
\hline
\end{tabular}

Localidades: U: Umariaçu; B: Belém; VD: Vendaval; CA: Compo Alegre; NI: Nova Itália; O: Ourique; VZ: Veneza; LA: Lago Acaratuba; IP Igarapé Passé; IA: Igarapé Assacaio; IC: Itho Cocao; SJ: Sāo Jorge; SD: Sōo Domingos; RJ : Rio Jacurapá; AP: Auati Paranó; S: Sabonete; IT: Igarapé Tonantins.

dos como genitores nas demais populações estudadas, e os de Umariaçu e Campo Alegre em apenas uma e duas respectivamente.

Informações quanto à fertilidade e mortalidade nestes grupos estão resumidas nas Tabelas $i \mathrm{e} 8$. Eles se caracterizam por apresentarem uma alta fertilidade (número médio de filhos nascidos vivos por mulher com idade superior a 15 anos : 5 ; entre as que completaram o período de reprodução: 7) e mortalidade relativamente baixa para pessoas que vivem em condições semelhantes (de 1.683 nascidos vivos, 421 ou $25 \%$ morreram antes da época de reprodução). Portanto, o número médio de filhos sobreviventes é alto: 4 considerando todas as famílias; 6 nas famílias completas. Deve mencionar-se, no entanto, que existe variação nas taxas de mortalidade
TABELA 7 - Número de filhos nascicios vivos em cinco poptilaçōes de indios Ticuna

\begin{tabular}{|c|c|c|c|c|}
\hline \multirow[b]{2}{*}{ Localidades } & \multicolumn{2}{|c|}{ Todas as familias } & \multicolumn{2}{|c|}{ Familias completas } \\
\hline & $\begin{array}{l}\mathrm{N} \cdot{ }^{\circ} \text { de } \\
\text { mulheres }\end{array}$ & $\begin{array}{l}N \circ \text { médio } \\
N V \pm E P\end{array}$ & $\begin{array}{l}\text { N.o de } \\
\text { mulheres }\end{array}$ & $\begin{array}{l}N \cdot{ }^{\circ} \text { médio } \\
N V \pm E P\end{array}$ \\
\hline Umariaçu & 127 & $5,5 \pm 0.3$ & 47 & $7,6 \pm 0,0$ \\
\hline Beiém & 54 & $5,5 \pm 0,4$ & 22 & $7.7 \pm 0.6$ \\
\hline Vendavai & 54 & $4.6 \pm 0,4$ & 21 & $7,4 \pm 0,5$ \\
\hline Campo Alegre & 68 & $4,7 \pm 0,4$ & 25 & $6,7 \pm 0,6$ \\
\hline Nova Itália & 22 & $5,2 \pm 0,6$ & 10 & $8,0 \pm 0,5$ \\
\hline Todos os grupos & 325 & $5,2 \pm 0,2$ & 125 & $7,4 \pm 0,2$ \\
\hline
\end{tabular}

NV: Nascidos vivos; EP: Erro padrăo da média.

entre localidades. Campo Alegre apresenta o valor mais baixo (decréscimo de $10 \%$, somente, em relação ao múmero médio de nascidos vivos nas famílias completas) e Belém o mais elevado ( $30 \%$-- Tabela 8$)$.

A esterilidade è pouco freqüente : somente 8 casais parecem ser estéreis, de um total de 320 com pelo menos três anos de coabitação. Surpreendentemente, 6 pertencem ao grupo de 67 casamentos registrados em Campo Alegre.

Na Tabela 9, é feita uma comparação entre os Ticuna e outras sete tribos de índios sul-americanos, quanto ao índice de Crow (1958) sobre a oportunidade de ação da selecão natural. Os Ticuna apresentam o índice mais baixo obtido até agora em populaçōes deste grupo étnico $(0,54)$. Isto se explica, em parte, pelas taxas de mortalidade baixas já mencionadas anteriormente; mas além disso, pela variância no número de crianças nascidas vivas em famílias completas $(8,3)$, que é apenas um pouco maior do que a média $(7,4)$.

\section{DIscussão}

O quadro geral obtido destes dados mos. tra que os Ticuna estão envolvidos, atualmen. te, em um ativo processo de "explosão demográfica". Nimuendaju (1952) estimou em 2.000 o número total destes índios vivendo no Brasil em 1942, sendo 1.000 em países vizinhos. Oliveira (1972), baseado em dados demográfi- 
TABELA 8 - Prole sobrevivente por mulher que teve ao menos um filho nascido vivo, em cinco populaçōes de índios Ticuna

\begin{tabular}{|c|c|c|c|c|c|c|}
\hline \multirow[t]{2}{*}{ Localidades } & \multicolumn{3}{|c|}{ Todas as famílias } & \multicolumn{3}{|c|}{ Familias completas } \\
\hline & $\begin{array}{l}\text { N. de } \\
\text { mulheres }\end{array}$ & $\begin{array}{l}\text { N.० médio } \\
F S \pm E P\end{array}$ & $\begin{array}{c}\text { Decréscimo } \\
(\% \mathrm{NV})\end{array}$ & $\begin{array}{l}\text { N.० de } \\
\text { mulheres }\end{array}$ & $\begin{array}{c}\text { No médio } \\
F S \pm E P\end{array}$ & $\begin{array}{c}\text { Decréscimo } \\
(\% \mathrm{NV})\end{array}$ \\
\hline Umariaçu & 125 & $4,4 \pm 0,2$ & 20 & 46 & $5.8 \pm 0,4$ & 24 \\
\hline Bolém & 53 & $3,9 \pm 0,3$ & 29 & 21 & $5.4 \pm 0.5$ & 30 \\
\hline Vendaval & 51 & $3,7 \pm 0,3$ & 20 & 21 & $5,3 \pm 0,4$ & 28 \\
\hline Campo Alegre & 61 & $4,3 \pm 0,3$ & 9 & 23 & $6,0 \pm 05$ & 10 \\
\hline Nova Itália & 22 & $4,0 \pm 0,5$ & 23 & 10 & $6,0 \pm 0,6$ & 25 \\
\hline Todos os grupos & 312 & $4,1 \pm 0,1$ & 21 & 121 & $5,7 \pm 0,2$ & 23 \\
\hline
\end{tabular}

FS: Filhos sobreviventes; EP: Erro padrāo da média; NV: Nascidos vivos.

TABELA 9 - Comparação entre os Tícuna e outras tribos sul-americanas, em relação à oportunidade para a seleção

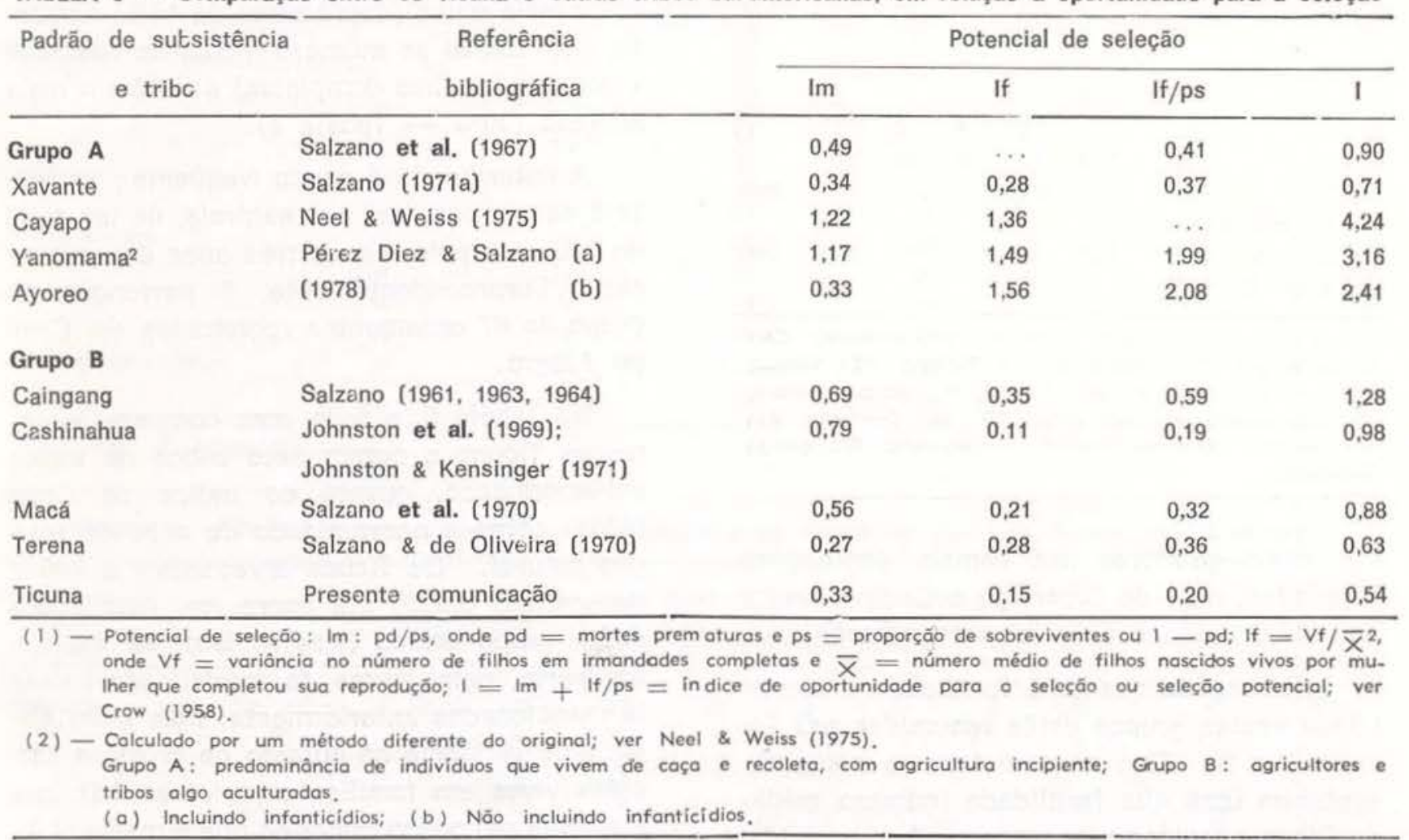

cos obtidos nos anos de 1959-1962, sugeriu que este total deveria ser $3.500-4.000$ em território brasileiro, na época; e o Padre E. Schwade, que realizou um recenseamento entre eles em 1974, chegou a um valor total de 11.000 (ver Oliveira, 1977). Os nossos resultados estão de acordo com este último valor: pelo menos 11.000 indios desta tribo estão vivendo atualmente no Brasil.
Alguns dos dados específicos obtidos por Oliveira (1964), em suas investigaçōes entre algumas das populaçöes agora estudadas por nós, são esclarecedores. Assim, seu recenseamento de Belém em 1959-62 forneceu um total de 438 pessoas, enquanto não menos de 888 foram registrados por nós e 1.309 por Oliveira (1977). O aumento no tamanho da comunidade de Umariaçu é ainda mais dramáti. 
co. Oliveira encontrou somente 268 pessoas, neste iugar, em 1959; três anos depois, este número havia crescido para 510 e nós registramos 1.247 individuos lá em 1975! Em 1959-62, Oliveira registrou como 399 o número de pessoas que viviam no Igarapé Preto ou São Jerónimo, e indivíduos pertencentes a este grupo contribuíram para a maioria dos fundadores da comunidade de Vendaval em 1972. Nós registramos neste lugar 793 pessoas, durante nosso trabalho de campo. Finalmente, Oliveira (1964) menciona 137 indios Ticuna vivendo próximo a Santa Rita do Weil na época em que realizou sua investigação, enquanto que, em Campo Alegre, situada próximo àquela cidade, nosso recenseamento (que não foi exaustivo) registrou 1.190 pessoas.

Estes elevados aumentos nos tamanhos das comunidades situadas ao longo do rio Soiimões são, em grande parte, devidos a duas causas principais. Em primeiro lugar, a liberação dos indios, dispersos sobre os pequenos tributários do Solimões, da "custódia" dos néo-brasileiros que controlavam as embo caduras destes rios. Como foi mencionaco na introdução, todas as trocas de bens em determinada época eram feitas através destas pessoas. O segundo fator está relacionado com o desenvolvimento, nesta área, da religião da Santa Cruz. Seu líder desempenhou papel importante na conscientização do índio sobre o seu próprio poder. Ele os exortou a viverem em comunidades grandes, a fim de se proteger do mundo exterior.

Mas estes aumentos não podem ser explicados somente em termos de migraçōes. A alta fertilidade desta tribo já havia sido notada por Oliveira (1964). Embora a taxa Ticuna năo alcance o valor huterita, de 10 criancas por mulher que terminou seu período reprodutivo (Eaton \& Mayer, 1953), seu valor ainda é bastante alto. Este fator, juntamente com a mortalidade, relativamente reduzida para grupos que vivem neste estágio cultural, bem como a baixa esterilidade, deve ter contribuído para o "boom" populacional. Talvez, a proximidade aos rios, que atuam como uma fonte rica em proteínas, possa ser responsável por estes eventos.

Como foi mencionado na introduçāo, as regras exogâmicas foram muito importantes para os Ticuna em épocas precedentes. A isto deveria acrescentar-se a facilidade de transporte, fornecida pelos rios. É, portanto, fácil explicar a alta percentagem de casamentos contraídos com pessoas nascidas em localidades diferentes, bem como o grande número de fontes que contribuíram para o reserva. tório gênico das comunidades de hoje. Mas existem diferenças entre aldeias quanto a este aspecto, provavelmente relacionadas com sua história e localização geográfica. Belém é a mais antiga das comunidades estudadas. Há informaçōes de que índios Ticuna trabalhavam neste local na década de 20 , embora o primeiro grande movimento de pessoas em direção ao mesmo ocorresse apenas na década de 30. A fundação de Umariaçu data da doação de uma extensa fazenda, feita por Joana Benage dos Santos, ao então Serviço de Proteçäo aos Índios. Este fato ocorreu em 1945. As outras três localidades estudadas detalhadamente por nós (Vendaval, Nova Itália e Campo Alegre) são todas muito recentes, iendo sido formadas em 1972, principalmente em conseqüência da peregrinação do Irmão José. Belém parece ser um centro de irradiação: as pessoas que nascem neste lugar migram seguidamente para outros grupos. A localização periférica de Umariaçu e Nova Itália, por outro lado, tem reflexos na matriz de migração. Elas recebem migrantes de muitos outros centros, mas são isoladas entre si (isto é, nenhuma pessoa nascida em Umariaçu casou-se em Nova Itália, por exemplo).

A realização de comparações com outras tribos sul-americanas fica prejudicada tanto pela excassez de dados como pela diferença na situação ecológica destes grupos. Se considerarmos, entretanto, somente tamanho da população e distribuição geográfica, podemos comparar os Ticuna com cinco outras tribos (informações pertinentes apresentadas em Salzano, 1971). A densidade populacional dos Ticuna é alta $(11.000 / 181.500=0,061$ habitantes por $\mathrm{km}^{2}$ ), sendo que somente os Terena, no sul do Mato Grosso, apresentam 
um indice mais alto $(0,089)$. No entanto, os Ticuna locomovem-se mais facilmente e, como foi dito, são culturalmente predispostos à exogamia.

Os agriculturalistas e as tribos algo aculturadas parecem apresentar, em geral, fertilidade e mortalidade mais altas do que grupos que utilizam a caça e a recoleta como meio de subsistência (ver Salzano, 1972); no entanto, como foi visto na Tabela 9, os índices de oportunidade para a seleção podem ser altos ou baixos, independentemente desta dicotomia. Os Ticuna, que dependem bastante da pesca e da ágricultura para a sua subsistência e têm uma longa história de contatos com năo-índios, apresentam um índice surpreendentemente baixo. Se relacionamos agora este fato à sua mobilidade e tamanho populacional relativamente altos, surge a possibilidade de existência de uma variabilidade genética significativa, com diferenças reduzidas entre aldeias.

\section{AGRADECIMENTOS}

Os estudos realizados pela expedição amazônica do Alpha Helix foram financiados pela Fundação Nacional de Ciências dos EE.UU., através dos auxílios OCE 74-02888 à Instituição Scripps de Oceanografia e OCE 75-21208 à Universidade de Michigan. Auxílios financeiros adicionais para o trabalho de campo foram fornecidos pela "National Science Foundation" e Conselho Nacional de Desenvolvimento Científico e Tecnológico. A Fundação Nacional do Índio forneceu permissão para o estudo dos índios, bem como outras facilidades. O Diretor e investigadores do Instituto Nacional de Pesquisas da Amazônia também auxiliaram de diferentes maneiras.

\section{SUMMARY}

The Ticuna Indians of Brazil are now a largely acculturated and integrated tribe situated for the most part in villages along the Solimões river. Demographic information collected in eight of their villages is reported here. For five of them detailed data concerning migration, fertility and mortality were obtained. The are characterized by a relatively large mobility. high fertility (mean number of livebirths per female of age 40 or more: seven), low $(2.5 \%)$ frequency of sterile couples; and relatively low mortality for groups living at this cultural stage $25 \%$ of deaths before the age of reproduction). This low mortality, and a relatively small variance in the number of liveborn children in completed families, lead to the lowest index of opportunity for selection obtained thus far in populations of South American Indians $(0,54)$.

\section{BIBLIOGRAFIA}

Crow, J.F.

1958 - Some possibilities for measuring selection intensities in man. Human Biology, 36 : $1-13$.

EATON, J.W. \& MAYER, A.J.

1953 - The social biology of very high fertility among the Hutterites. Hum. Biol., 25. 206-264.

JoHnSTON, F.E. \& KENSINGER, K.M.

1971 - Fertility and mortality differentials and their implications for microevolutionary change among the Cashinahua. Hum. Biol., 43:356-364.

JOHNSTON, F.E.; KENSINGER, K.M.; JANTZ, R.L. \& WALKER, G.F.

1969 - The population structure of the Peruvian Cashinahua: demographic, genetic and cultural interrelationships. Hum, Biol., 41:29-41.

LoukotKa, C.

1968 - Classification of South American Indian languagens. Los Angeles, Latin American Center, University of California.

NeEL, J.V. \& WeIsS, K.M.

1975 - The genetic structure of a tribal population, the Yanomama Indians. XII. Biodemographic Studies. Am. J. Phys. Anthrop., 42:25-52.

NimuendaJu, C.

1948 - The Tucuna. In: Steward, J. H. ed. Handbook of South American Indians. Washington D.C., Smithsonian Institution. v. 3. p. $713-725$.

1952 - The Tukuna. Berkeley, Univ. California Publ, Am. Archaeol, Ethnol.

Oliveira, R. CARDoso dE

1964 - O índio e o mundo dos brancos. São Paulo, Difusão Européia do Livro.

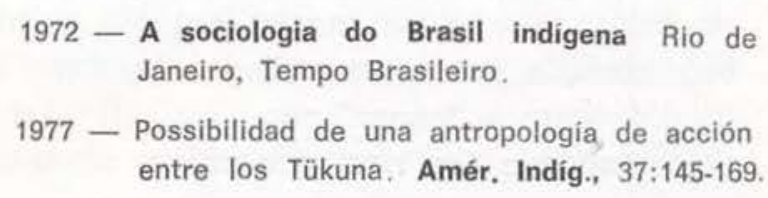
Janeiro, Tempo Brasileiro.

1977 - Possibilidad de una antropología de acción entre los Tükuna. Amér. Indíg., 37:145-169. 
Oliveira Filho, J. PACHeCO de

1977 - As facçōes e a ordem política em uma reserva Tükuna. Dissertação de Mestrado. Brasília, Universidade de Brasília.

Perez Diez, A.A. \& Salzano, F.M.

1978 - Evolutionary implications of the ethnography and demography of Ayoreo Indians. J. Hum. Evol., 7:253-268.

SAlzano, F.M.

1961 - Studies on the Caingang Indians. I. Demography. Hum. Biol., 33:110-130.

1963 - Selection intensity in Brasilian Caingang Indians. Natura, 199:514.

1964 - Demographic studies on Indians from San. ta Catarina, Brasil. Acta Genet. Med. Gemellol., 13:278-294 .

1971a - Demographic and genetic interrelationships among the Cayapo Indians of Brasil. Soc. Biol., 18:148-157.

1971b-Genetic polymorphisms in Brazilian populations. In: Salzano. F. M. ed. - The ongoing evolution of Latin American populations. Springfield, Charles C. Thomas. p. 631-659.
1972 - Genetic aspects of the demography of American Indians and Eskimos. In: Harrison, G.A. \& Boyce, A.J. eds. - The structure of human populations. Oxford. Clarendon Press. p. 234-251.

Salzano, F.M. \& Oliveira, R.C. DE

1970 - Genetic aspects of the demography of Brasilian Terena Indians. Soc. Biol., 17:217-223.

Salzano, F.M.: Moreno, R.; Palatnik, M. \& GeRshowITZ, H.

1970 - Demography and H-Lea salivary secretion of the Macá Indians of Paraguay. Am. J. Phys. Anthrop., 33:383-388.

Salzano, F.M.: Neel, J.V. \& Maybury-Lewis, D.

1967 - Further studies on the Xavante Indians. I. Demographic data on two additional villages: genetic structure of the tribe. Am, J, Hum. Genet., 19:463-489.

(Aceito para publicação em 9/12/78) 